\title{
DEBERES PROCESALES DE LAS PARTES EN EL PROCESO CIVIL CHILENO: REFERENCIA A LA BUENA FE PROCESAL Y AL DEBER DE COHERENCIA
}

\author{
Francesco Carretta Muñoz*
}

\begin{abstract}
RESUMEN
Se examina la noción de deber. Para su determinación se efectúa un análisis comparativo con las obligaciones y las cargas. De la confrontación se extrae un rasgo moral presente en este imperativo que le confiere singularidad frente a los demás factores. Esta característica ética tiene directa relación con la buena fe procesal que se ubica en el nivel axiológico del proceso.
\end{abstract}

DEBERES PROCESALES - CARGA PROCESAL - BUENA FE PROCESAL

\author{
Procedural duties of the parties in the civil Chilean process: \\ it relationship with procedural good faith and with the duty of coberence
}

\begin{abstract}
This paper explores the concept of procedural duty, by means of a comparative analysis with the notions of obligation and load. The author concludes that the first has a moral feature that distinguishes it. This ethical quality has a direct relationship with procedural good faith.
\end{abstract}

\author{
PROCEDURAL DUTIES - PROCEDURAL BURDENS - \\ PROCEDURAL GOOD FAITH
}

\footnotetext{
* Abogado, estudiante de doctorado en derecho en la Pontificia Universidad Católica de Valparaíso, Profesor asistente de la cátedra de derecho procesal civil de la Pontificia Universidad Católica de Valparaíso. Juez del tribunal de familia de Valparaíso, Chile, fcarretta@pjud.cl, El autor agradece las observaciones efectuadas por el profesor Dr. Álvaro J. Pérez Ragone y por don Darío Carretta. Artículo recibido el 15 de marzo de 2008 y aceptado para su publicación por el Comité Editorial el 27 de mayo de 2008.
} 


\section{INTRODUCCIÓN}

$\mathrm{N}$ o se puede concebir que el carácter formal del proceso lo reduce a una ordenación técnica de fases instituidas por el legislador. ${ }^{1}$ Observar la manera como se desenvuelve en la práctica implica ver un dinamismo conductual y psicológico que se produce entre personas que someten la decisión de sus problemas a otra, a través de un hilo conductor asentado en normas y principios que confieren progresividad a sucesivos instantes dialécticos. ${ }^{2}$ El objetivo es la decisión del conflicto, que interesa al Estado como receptor de una conciencia colectiva de justicia social. Los vectores que transitan y friccionan en esta dinámica son conductas humanas plasmadas en categorías conceptuales que han surgido al amparo de procesos lógicos de partición, división y clasificación. Se escucha hablar en el proceso de derechos, deberes, facultades, poderes, gravámenes, y cargas que mirados dentro de su esfera - procesal- detentan un régimen radicalmente diverso del derecho de fondo. ${ }^{3}$ La ciencia procesal se ha centrado primordialmente en el desarrollo de una categoría conductual a partir de la obra de Goldschmidt: la carga. Se yuxtaponen además las obligaciones y los deberes cuyo estudio no ha estado al mismo nivel de aquella. Por otra parte, dentro de esta estructura ¿qué rol juega el moralmente necesario desenvolvimiento del proceso? Si bien la lealtad en el proceso se comienza a estudiar ya en la primera mitad del siglo pasado, se escuchan con mayor fuerza hoy en día expresiones como: la buena fe procesal, el abuso del proceso, dolo procesal, etc. Es palpable por los operadores el actual uso indebido del proceso en base a acciones dilatorias, contumaces o dolosas. En nuestro país existen escasas referencias al tema. ¿La buena fe es un principio, un deber una obligación o una carga? La elección es relevante pues dogmáticamente cada imperativo merece una distinción con importantes consecuencias prácticas. Por ahora, intuyo que la mayor correlación se da entre la buena fe y el deber, es por eso que este estudio se avocará preponderantemente a estos conceptos y sus puntos de encuentro.

La propuesta que se entrega en esta pesquisa pretende ser teórica, en el estudio y descripción de los elementos conductuales. Dogmática en la identificación de una faz axiológica en el proceso. También espero que tenga relevancia práctica en dos aspectos. El primero vinculado a las notas críticas que, en relación al objeto de esta disquisición, se efectuarán sobre el actual derecho procesal civil nacional, con propuestas de solución y análisis jurisprudencial, y, el segundo, relacionado a las anotaciones que se realizarán en función del anteproyecto del Código procesal civil.

\footnotetext{
${ }^{1}$ Cfr. Alvaro de Oliveira, Carlos Alberto, "Poderes del juez y visión cooperativa del proceso", en Revista peruana de derecho procesal, VII, Palestra, Lima, 2005, p. 17.

2 Vid. D’Ors, Álvaro, Una introducción al estudio del derecho, Ediciones Universitarias de Valparaíso, Valparaíso, 2003, p. 30.

3 " $E$ ad esprimere le posizioni soggettive elementari che ne sorgono, si sentirá parlare in pratica di diritti e di doveri, di facoltá, di poteri, di oneri, di soggezioni processuali. É una terminologia che non si riesce ad eliminare ne a sostituire. Bisogna porre per ció l'accento sulla qualifica di "processuali" ed evitare cosí di confundere quelle posizioni con le altre... omonime del diritto sostanziale, poiché cause ed effetti di quelle posizioni (processuali) si esauriscono normalmente (e s alvo le ripercussioni o le proiezioni esterne che vedremo) nella sfera interna del rapporto e dei suoi fini specifici e sono regolate pertanto da un regime tutto proprio e radicalmente diverso da quello del diritto sostanziale”. Redenti, Enrico, Diritto proccesuale civile, I, Giuffrè, Milano, 1957, pp. 120-125.
} 
La metodología utilizada es comparativa a partir de la noción de carga procesal. Su cimiento resulta óptimo para el cotejo con las demás categorías conductuales. Se desarrollarán en la obra siete puntos distribuidos en tres bloques orientados en orden progresivo. El primero, referido al esbozo de las cargas y las obligaciones como paso previo a la delimitación del concepto de deber. El segundo, dedicado a depurar la noción de deber jurídico procesal, mediante el análisis comparativo con los demás elementos, complementándose de paso el contenido de todos los vectores. El tercero estará dirigido a estudiar la buena fe como fuente de los deberes en el proceso civil y en particular el deber de coherencia.

\section{BREVE REFERENCIA HISTÓRICA}

Creo necesario hacer, no obstante ya bastante conocido, un pequeño encuadre histórico sobre la cuestión. Las principales teorías que explican la naturaleza jurídica del proceso han reconocido que en él existen imperativos. ${ }^{4}$ La tesis de la "situación jurídica" planteada por Goldschmidt ${ }^{5}$ postula que en el proceso sólo se desenvuelven cargas, expectativas y caducidades, y si bien reconoce deberes y obligaciones en su interior, estos son vistos como ligámenes de hecho. ${ }^{6}$ La teoría de la "relación jurídica" desarrollada por Von Bülow, ${ }^{7}$ postula que en el proceso existe una relación jurídica en la cual las partes entre sí y ellas con respecto al juez se hallan ligadas por una serie de vínculos, no sólo de carácter material sino también de carácter jurídico procesal. Ambas posturas de principios del siglo XX se han mantenido hasta ahora con algunas variaciones y corrientes, ${ }^{8}$ pero inalteradas en lo esencial. Entre las dos predomina la tesis de la relación jurídica, puesto que actualmente no se discute que el proceso en su interior contiene imperativos que ligan a las partes y a éstas con el juez en una interconexión de carácter público. Lo público porque el proceso es un método, cuya función institucional llamada jurisdicción a cargo del Estado es primordialmente la resolución de conflictos. ${ }^{9}$ Luego del estudio

${ }^{4}$ Vid. Monroy Gálvez, Juan, Introducción al proceso civil, Temis, Bogotá, 1996, p. 126.

5 "La antítesis del derecho procesal es la carga procesal, es decir, la necesidad de prevenir un perjuicio procesal, $y$, en último término, una sentencia desfavorable, mediante la realización de un acto procesal. Estas cargas son imperativos del propio interés”. Y por otra parte es categórico en afirmar que "no incumbe a las partes deberes procesales”. Goldschmidt, James, Principios generales del proceso, I: Teoría general del proceso, Ejea, Buenos Aires, 1961, p. 21.

${ }^{6} \mathrm{Ibid}$, pp. 91-110.

${ }^{7}$ Von Bülow, Oskar, Excepciones y presupuestos procesales, Ejea, Buenos Aires, 1964.

${ }^{8}$ En su tiempo Couture observa que entre ambas posturas -situación y relación- existe una discusión intransigente, imponiéndose en mayor medida esta última. Couture, Eduardo, Introducción al estudio del proceso civil, Arayú, Buenos Aires, 1953, p. 48.

${ }^{9}$ Cfr. Comoglio, Luigi Paolo, Ferri Corrado, Taruffo Michele, Lezioni sul processo civile, Vol. 1, Ed. Il mulino, Bologna, 1995, pp. 17 y 20; Monroy Gálvez, Juan, cit. (n. 4), p. 189. 
de Carnelutti en sus obras Sistema ${ }^{10}$ e Instituciones, ${ }^{11}$ y Couture en sus Estudios de derecho procesal civil ${ }^{12}$ y Fundamentos de derecho procesal civil, ${ }^{13}$ no se ha avanzado en la construcción de los imperativos en referencia para la adecuada conformación de un sistema jurídico procesal civil. ${ }^{14,15}$ Quizá se piense que lo dicho por los maestros es suficiente; ${ }^{16}$ sin embargo, una lectura de sus obras presenta a mi entender algunos inconvenientes. ${ }^{17}$

\footnotetext{
${ }^{10}$ Carnelutti, Francesco, Sistema de derecho procesal civil, Uthea, Buenos Aires, 1944, tomos I, II y III. Passim.

${ }^{11}$ Carnelutti, Francesco, Instituciones del proceso civil, I, Ejea, Buenos Aires, 1959. Passim.

12 Couture, Eduardo, Estudios de derecho procesal civil, III, Ediar, Buenos Aires, 1948. Sobre uno de los tópicos tratados en este estudio, cual es el deber de decir la verdad en el juicio civil, se refiere Niceto Alcalá-Zamora y Castillo quien estima que el trabajo de Couture en lo central alude a la moralización del proceso civil. Alcalá-Zamora y Castillo, Niceto, "Ensayos de derecho procesal", en Revista de jurisprudencia argentina, Buenos Aires, 1944, pp. 639-641.

${ }^{13}$ Couture, Eduardo, Fundamentos del derecho procesal civil, Depalma, Buenos Aires, 1958.

${ }^{14}$ Cuando hablo de "sistema" he seguido el estudio y explicaciones de Mario Losano, quien afirma que el desarrollo que este concepto ha tenido a través de la historia del pensamiento jurídico, en definitiva ha cristalizado en la formulación de una teoría general del sistema externo entendido este como una exposición ordenada de una disciplina, en este caso del derecho, que consta de axiomas (puntos de partida del discurso) y de teoremas (conclusiones extraídas aplicando la lógica) y cuyos requisitos son la coherencia, la completitud y la independencia de los axiomas. Consideraciones que según el autor citado están también presentes en Kohler al decir éste que la investigación jurídica debe conducir a la construcción del proceso civil, porque un derecho procesal sin construcción degenera en un utilitarismo descriptivo. Losano, Mario G., Sistema e struttura nel diritto, I: Dalle origine alla scuola storica, Giuffrè, Milano, 2002. Passim y pp. 300-301.

${ }^{15}$ Carnelutti, en su época, señala que el tema de las obligaciones procesales es el que menos se ha investigado. Cfr. Carnelutti, Francesco, Sistema de derecho procesal civil, III, Uthea, Buenos Aires, 1944, p. 95.

${ }^{16}$ Ejemplo de ello es que el trabajo que el profesor Picó realiza sobre la buena fe procesal para estudiar su configuración en carga, deber y obligación señala: "asumiendo los planteamientos desarrollados por Couture" Picó I Junoy, Joan, El principio de la buena fe procesal, Bosch, Barcelona, 2003, pp. 117-119. También se advierte el mismo planteamiento en: Masciotra, Mario, La conducta procesal de las partes, Ad-hoc, Buenos Aires, 2005, pp. 41- 48. Reimundin, Ricardo, Derecho procesal civil, I, Viracocha, Buenos Aires, 1956, pp. 127-135.

${ }^{17}$ Couture define en su obra Fundamentos del derecho procesal civil los deberes procesales como: "aquellos imperativos establecidos a favor de una adecuada realización del proceso. No miran tanto al interés de los litigantes como al interés de la comunidad" (p. 209) y obligaciones como "aquellas prestaciones impuestas a las partes con ocasión del proceso". Couture, Eduardo, cit. (n. 13), pp. 209 y 210. Sin embargo, cuando los inserta en el ordenamiento jurídico, como se aprecia en su estudio "El deber de las partes de decir la verdad" (Cit. (n. 12) pp. 235-258) estima que la lealtad, verdad o probidad procesal puede ser obligación, deber o carga según lo instituya el ordenamiento en que esté inserta. Cuestión que, como se verá en este trabajo, no es técnicamente correcta, porque dichos valores, independiente del ordenamiento jurídico en que se encuentren, sólo pueden constituir deberes procesales emanados del principio de la buena fe procesal. La asimilación se constata también en: Cappelletti, Mauro, Las sentencias y las normas extranjeras en el proceso civil, Ara, Lima, 2006, p. 178; en la traducción al español de: Rosenberg, Leo, Tratado de derecho procesal civil, I, Ejea, Buenos Aires, 1955, p. 11.
} 


\section{ESTUDIO Y APLICACIÓN DE LOS CONCEPTOS DE CARGAS Y OBLIGACIONES EN EL ORDENAMIENTO PROCESAL CIVIL CHILENO, COMO PASO PREVIO A LA DELIMITACIÓN DEL CONCEPTO DE DEBER}

\section{III.A. La noción de carga procesal y su inconveniente con la denominada contestación ficta de la demanda}

La persona que a través de su facultad adjetiva ${ }^{18}$ reclama la tutela de un derecho que entiende transgredido normalmente concurrirá al órgano jurisdiccional. Está dentro de su libertad hacerlo o no hacerlo. Inmediatamente, dentro de la misma libertad, ya que no está obligada tampoco a seguir adelante con el reclamo intentado, adquirirá el segundo elemento en concatenación con el anterior, su carga de comparecer, que genera a su vez otra, la carga de su opositor, una vez noticiado, de asistir a la sede jurisdiccional a defenderse. ${ }^{19}$ Este factor es uno de los pilares sobre los que se ha construido la ciencia procesal. Tiene un nítido origen en la obra de Goldschmidt. ${ }^{20}$ Algunas de las definiciones sobre el particular ${ }^{21}$ convergen en que por este imperativo el sujeto está recomendado

${ }^{18}$ Con esto me refiero a los derechos subjetivos procesales. El concepto de derecho subjetivo no tiene un claro significado y alcance en la ciencia del derecho, a pesar que es un vocablo de recurrente utilización en sus distintas áreas. Tampoco se desconoce su vital importancia; con razón se ha dicho que "El derecho subjetivo reina como amo del pensamiento jurídico". (Villey, Michel, Estudios en torno a la noción de derecho subjetivo, Ediciones Universitarias de Valparaíso, Valparaíso, 1976, p. 151.) No obstante, estudios sobre el particular revelan un aspecto común: el derecho subjetivo está estrechamente emparentado con el concepto de facultad. A mi entender, el derecho subjetivo se relaciona con una potencia o poder inherente al ser y propia de la libertad. Carnelutti señala que "la acción es el derecho subjetivo procesal de las partes" y que es una noción ya identificada en cuanto es claramente distinguible el derecho subjetivo material (ius) que la parte solicita sea tutelada en juicio, del derecho subjetivo procesal mediante el cual se hace valer (actio), aun cuando la actio también es ius. (Carnelutti, Francesco, cit. (n. 11), p. 315) y en este sentido, en el ámbito procesal civil, el concepto aparece emparentado a la acción. Para este trabajo es útil un aspecto indiscutido de la acción. Esta sirve de puerta de entrada al proceso y se concreta en la medida que el titular, dentro de un Estado de derecho, manifieste su potestad, atendidas las circunstancias, a través de la solicitud de tutela en cualquiera de sus especies: anticipatoria, constitutiva, declarativa, condena, etc. Interpuesto el requerimiento de protección ante los órganos jurisdiccionales, como una consecuencia natural de la vinculación jurídica entre éste y los particulares, la naturaleza del derecho subjetivo es necesariamente de carácter público.

${ }^{19}$ Se entiende sin perjuicio de la jactancia o el litis consorcio pasivo necesario impropio.

${ }^{20}$ Goldschmidt señala: "la antitesis del derecho procesal es la carga procesal, es decir, la necesidad de prevenir un perjuicio procesal, y, en último término, una sentencia desfavorable, mediante la realización de un acto procesal. Estas cargas son imperativos del propio interés". Goldschmidt, James, cit. (n. 5), p. 91.

${ }^{21}$ Carnelutti expone: "bablo de carga cuando el ejercicio de una facultad aparece como condición para obtener una determinada ventaja; por ello la carga es una facultad cuyo ejercicio es necesario para el logro de un interés. Obligación y carga tienen en común el elemento formal, consistente en el vínculo de la voluntad; pero difieren en el elemento substancial, porque cuando hay obligación, el vínculo se impone para la tutela de un interés ajeno, y para la tutela de un interés propio, cuando se trata de la carga". Carnelutti, Francesco, cit. (n. 11), p 65. En esta obra a su vez distingue los procesos de conocimiento y de ejecución y en ambos la carga de la instrucción la descompone de la siguiente manera: carga de la razón, de la prueba, de la elección de los bienes (en el proceso de ejecución), de la impugnación, y del impulso procesal (que se divide en carga de notificación, actos preparatorios de la audiencia, de la asunción de las pruebas, solicitud de venta forzosa, etc.); Cappelletti alude a las consecuencias desfavorables que para el infractor de una carga puede presentarse, Cappelletti, Mauro, cit. (n. 17) p. 178; 
por el ordenamiento procesal, a la tarea de hacer progresar el proceso, a través de la ejecución de una conducta que a él es útil, y cuya infracción o desembarazamiento, que a su vez constituye el mecanismo de rebeldía, sólo afectará su propio interés. Ello porque la consecuencia será dependiente o provendrá de sí mismo que, en un primer momento será la preclusión y en último caso será la mayor posibilidad de la pérdida del litigio a través de una sentencia desfavorable.

Nuestro ordenamiento jurídico regula y reconoce este instituto en una serie de disposiciones rituales siendo las cargas principales: fundamentar la demanda, probar, contestar y comparecer. Respecto a estas dos últimas es preciso notar que el Código de procedimiento civil no se refiere expresamente al efecto de la rebeldía del demandado o contumacia de la parte. ${ }^{22}$ El vacío es llenado por interpretaciones ${ }^{23}$ que estiman que el silencio del demandado se traduce en su negación, cuestión que es recogida por la jurisprudencia nacional. ${ }^{24}$ Lo anterior, de la forma que se verifica en el ordenamiento nacional, ${ }^{25}$ confrontándolo con los elementos esénciales sobre los que se asienta la noción de carga, produce un importante inconveniente. ${ }^{26}$ ¿Es en nuestro derecho la comparecencia y contestación efectivamente una carga? El sistema de cargas cumple con una función impulsiva de la parte. Mediante ella el ordenamiento procesal civil propende a incentivar una actitud que contribuya a la consecución progresiva de los actos del proceso. En ese sentido, la constitución de la rebeldía de las partes, que es el

Couture define a la carga como el imperativo del propio interés siendo su concepción no sólo en la definición parecida a la de Goldschmidt sino que además en su desarrollo, sin embargo, el maestro uruguayo agrega que existe una estrecha relación entre la carga con el impulso procesal en la medida que el proceso avanza en virtud de aquellas. Couture, Eduardo, cit. (n. 13), p. 211; Sentís Melendo, ve en la idea de carga aforismos jurídicos basados en la idea de que el derecho no favorece a los torpes y como la manifestación más eximia del liberalismo en el proceso. Sentís Melendo, Santiago, Teoría y práctica del proceso (Buenos Aires, 1959), III, pp. 87 y 91. En el mismo sentido, Reimundin, Ricardo, cit. (n. 16), pp. 128 y sgts. Procesalistas recientes aluden a la misma idea: Picó Junoy, Joan, cit. (n. 16), p. 117; Maurino, Alberto Luis, Abuso del derecho en el proceso, La ley, Buenos. Aires, 2001, p 8; Masciotra, Mario, cit. (n. 16) p. 43;

${ }^{22}$ Vid. Giannozzi, Giancarlo, La contumacia nel processo civile, Giuffrè, 1963; Satta, Salvatore, Diritto processuale civile, Cedam, Padova, 1957, pp. $304-305$.

${ }^{23}$ Entre otros, Carocca Perez, Alex, Manual de derecho procesal, II, LexisNexis, Santiago, 2003.

${ }^{24}$ C.S. 8 de agosto de 1991, en www.lexisnexis.cl, número identificador 11419, visitado el 15 de agosto de 2007; C.S. 21 de noviembre de 2001, en www.lexisnexis.cl, número identificador 22976, visitado el 15 de agosto de 2007; C.S. 10 de octubre de 2001, en www.lexisnexis.cl, número identificador 22527, visitado el 15 de agosto de 2007; C.S. 26 de septiembre de 2006, en www.lexisnexis.cl, número identificador 35569 , visitado el 15 de agosto de 2007.

25 En los ordenamientos jurídicos europeos, como señala el profesor Pérez Ragone, refiriéndose al procedimiento monitorio, los sistemas existentes de regulación de la rebeldía o contumacia, le asignan a la actitud del rebelde el carácter una confesión tácita (ficta confessio) o como reconocimiento (ficta litis contestatio). Pérez Ragone, Álvaro J., "En torno al procedimiento monitorio desde el derecho procesal comparado europeo: caracterización, elementos esenciales y accidentales", en. Revista de derecho de la Universidad Austral de Chile (Valdivia), jul. 2006, vol.19, no.1, pp.205-235.

${ }^{26}$ También hay autores que opinan que la contestación ficta constituye una tergiversación al principio procesal de la verdad formal que se busca en el proceso civil, pues la contestación de acuerdo a la lógica debería en realidad equivaler a una aceptación. Castellón Munita, Juan Agustín, Los principios procesales, en Gaceta Jurídica, N²95, 2005, p. 30. 
incumplimiento o desembarazamiento de la carga, debiera tener ante todo, un claro efecto disuasivo, una situación desventajosa para el infractor que en último caso se constituirá en una sentencia adversa. Sin embargo, vemos que en nuestro ordenamiento, frente al vacío legal, al haberse establecido al menos jursiprudencialmente el sistema de negación tácita, no necesariamente se producirá una consecuencia adversa para el no compareciente o incumplidor de la carga de presentarse al juicio y contestar, exceptuando la preclusión, porque incluso puede serle mucho más ventajoso no comparecer, de manera que entendida su actitud como una negación pura y simple, asumirá el litigante contrario una carga mayor. Ello toda vez que deberá hacerse cargo preponderantemente de la prueba e incluso el contumaz puede ganar el pleito aun en su ausencia. Lo anterior tampoco resulta justo porque el desobediente rompe el principio de colaboración que sí es cumplido por su contraparte al seguir adelante con el proceso. ${ }^{27}$

Fuera del defecto anotado, la interacción de cargas en el proceso se produce al amparo del ordenamiento normativo procesal. El artículo 1698 del Código Civil y normas atingentes del Código de Procedimiento Civil y otros cuerpos normativos se amoldan a los patrones clásicamente citados, en ellas el juez no es partícipe directo, con lo que quiero decir que no asume ninguna carga. Distinto es que el juez deba ir delimitando los efectos de ella en cuanto verificar su cumplimiento o incumplimiento para luego asignarle una consecuencia principalmente a través de la constatación del sistema preclusivo y eventual sentencia de absolución. La conducta que el juez asume en la utilización de dichos institutos, como me referiré más adelante, no es una carga o una obligación, sino un deber. Cargas y obligaciones competen únicamente a las partes. Por último, de la forma que se ha descrito esta categoría conductual, su fundamento se localiza en la satisfacción del interés de su titular. Él es el único a quien favorece o perjudica su conducta según la mayor o menor pasividad que asuma.

\section{III.B. Obligaciones procesales}

En términos generales, cuando se alude al contenido de una obligación, se apunta a un vínculo jurídico, ${ }^{28}$ entre personas determinadas. Una se encuentra en la necesidad

${ }^{27}$ El anteproyecto del Código Procesal Civil establece en su artículo 254 que: "Cuando el demandado debidamente emplazado no comparezca dentro del plazo correspondiente, se seguirá el proceso en su rebeldía con las consecuencias que la ley determine según los casos para cada procedimiento. En los procesos declarativos, la rebeldía del demandado importará una negación de los hechos afirmados por el actor en su demanda, pero no podrá rendir prueba en juicio al no haberla ofrecido en la contestación, a menos que se trate de pruebas supervenientes o referidas a hechos nuevos a los mencionados por la contraparte en la demanda, en cuyo caso podrán ser propuestas posteriormente”. El texto corresponde al documento consultado, el 18 de agosto de 2007, electrónicamente en http://www.minjusticia.cl/AnteproyectoCoProCivi. Esta disposición no es satisfactoria porque expresamente establece el defecto de la negación tácita para la rebeldía.

${ }^{28}$ Couture describe esta categoría como: "La prestación impuesta a las partes con ocasión del proceso cuya infracción acarrea una consecuencia económica a favor de la parte contraria, como la condena en costas o el pago de una indemnización”. Couture, Eduardo, cit. (n. 17). Esta definición clásica la comparto en el sentido en que no veo otras obligaciones en el proceso que las dos que señala Couture pero, en mi opinión, carece de la mención a un elemento esencial y diferenciador: el vínculo. 
de efectuar una prestación a favor de la otra. ${ }^{29}$ Si trasladamos esta noción, propia del derecho de fondo, al proceso, sirve en la medida que se adapte a sus contornos. En un primer análisis es innegable que al interior del proceso se forman vínculos entre personas. El tipo de vínculo, descartando en general el propio de la "relación jurídica", es aquel que pone a una de las partes en la necesidad de efectuar una prestación a favor de su contendor. Indagando entre quienes se forman este tipo de conexión vemos que la figura del juez debe ser descartada, puesto que éste no debe ejecutar ningún tipo de prestación a favor de ellas. El juez en su misión de resolver la contienda sometida a su conocimiento y hacer progresar el litigio sólo adquiere deberes. (Ver cap. IV.A infra) Entonces, por defecto, los únicos quienes pueden adquirir obligaciones en el proceso son las partes. Ellas en ciertas ocasiones, pueden quedar vinculadas por algunas causas que emanan del mismo proceso.

Se progresa en la clarificación de esta categoría si se coteja con el concepto de carga. Desde luego no hay ninguna coincidencia con el concepto de derecho subjetivo procesal desde que aquel no impone, per se, vínculos de ninguna especie. La carga se basa en un interés y no en un vínculo. El interés se genera sólo respecto del sujeto interesado y no entre más de una persona como en el caso de la obligación. El interés se constituye en un elemento individual, mucho más amplio y subjetivo que el vínculo, puesto que atiende a las motivaciones del sujeto por generar el desarrollo del proceso. El sujeto se autoimpone la exigencia. Esta libertad no está presente en el concepto de obligación porque el ligamen que genera revela que al menos una persona exigirá a otra -el obligado- el cumplimiento de una prestación procesal. Otra diferencia se aprecia en las consecuencias que se generan en uno u otro caso. Tanto la preclusión como la pérdida del litigio son las consecuencias asumidas por quien desembaraza una carga; a contrario, quien las cumple estará en mejor pie de obtener en juicio, o de no quedar entrampado por el efecto impeditivo de actuación propio de la preclusión. Ninguno de estos elementos se acepta como fruto del incumplimiento de una obligación, ya que cualquiera sea el evento el individuo incumplidor estará compelido, en último caso, compulsivamente al cumplimiento exacto del contenido de aquello a lo que está obligado.

Los efectos y las causas de lo planteado hasta ahora sólo pueden verse, a mi entender, en dos institutos: ${ }^{30}$ las costas y las indemnizaciones originadas intraproceso. ${ }^{31}$ Lo

${ }^{29}$ Como señala Abeliuk, se habla de obligación cuando un individuo está o se encuentra en la necesidad de actuar en determinada forma por razones de conveniencia social u otro motivo. La definición más acostumbrada en derecho civil de obligación es la que la considera como un vínculo jurídico entre personas determinadas, en virtud del cual una de ellas se coloca en la necesidad de efectuar a otra una prestación que puede consistir en dar, hacer o no hacer una cosa. Abeliuk Manasevic, René, Las obligaciones, I, Editorial Jurídica de Chile, Santiago, 1993, p. 29.

${ }^{30}$ Ibid, cit. (n. 28)

${ }^{31}$ El profesor Tavolari observa que en el caso de las costas debe estarse al fundamento privatístico o publicista que sobre las mismas se ha expuesto por la doctrina, en cuanto que para el primer caso de una noción resarcitoria o indemnizatoria y para el otro el caso de una sanción procesal, no obstante, como él mismo señala, prefiero eludir el debate sobre el problema ya que en uno u otro caso igualmente le es indiferente a este estudio, toda vez que cualquiera sea la situación es indesmentible que las costas crean un vínculo entre 
anterior puede parece una repetición viciosa porque las costas en el fondo son indemnizaciones, sólo que compensatorias en el monto de los gastos originados en el proceso. Por lo tanto, aclaro que cuando aludo a las indemnizaciones, sin otra denominación, me refiero a aquellos montos que se deben satisfacer en el proceso que van más allá de meros trámites, es decir, en aquellos casos que se ocasiona lesión a los intereses extrapatrimoniales de una de las partes. En los ordenamientos procesales civiles italiano ${ }^{32}$ y brasileño ${ }^{33}$ cuando uno de los litigantes procede con mala fe o culpa grave, se produce un efecto indemnizatorio a favor del perjudicado, y en el fondo una relación crédito débito entre dos personas, cuya fuente es el proceso. El Código de Procedimiento Civil chileno no contempla indemnizaciones a favor de una de las partes del proceso por la actitud dolosa asumida por la otra, en el caso que uno de los litigantes interponga su acción y con su proceder ocasione perjuicio a la otra. Sí se observa un caso en que una de las partes puede ser condenada al pago de los perjuicios que cause cuando solicita y obtiene medidas prejudiciales y después no deduce demanda oportunamente, o no pide en ella que continúen en vigor las medidas precautorias decretadas, o al resolver sobre esta petición el tribunal no las mantiene. ${ }^{34}$ Sin embargo, la determinación de la responsabilidad en esos casos debe hacerse en juicio diverso.

En cuanto a las costas en el título XIV del libro I del Código procedimental, se establece un orden de cuyo articulado se desprende claramente que el pago de aquellas obedece al reembolso de los gastos en que los litigantes incurren con ocasión del proceso, los que son divididos en procesales y personales. Por consiguiente, quien debe asumir su pago es por regla general el perdedor, quien en dicho evento debe cancelarlas a favor del vencedor. También se observa fuera del título XIV, lo preceptuado en el artículo 337 que contiene la imposición de una obligación referente a las costas, aunque la disposición no lo dice expresamente, que condena a la parte que solicita término extraordinario de

el obligado a pagarla y el contendor victorioso. Tavolari Oliveros, Raúl, Estudios de derecho procesal, Edeval, Valparaíso, 1990, p. 173.

32 Codice di procedura civile, "Art. 96 (Responsabilitá aggravata) Se risulta che la parte soccombente ha agito o resistito in giudizio con mala fede o colpa grave, il giudice, su istanza dell'altra parte, la condanna, oltre che alle spese, al risarcimento dei danni, che liquida, anche di ufficio, nella sentenza. Il giudice che accerta l'inesistenza del diritto per cui e' stato eseguito un provvedimento cautelare, o trascritta domanda giudiziaria o iscritta ipoteca giudiziale, oppure iniziata o compiuta l'esecuzione forzata, su istanza della parte danneggiata condanna al risarcimento dei danni l'attore o il creditore procedente, che ha agito senza la normale prudenza. La liquidazione dei danni e' fatta a norma del comma precedente". Carpi, Federico-Colesanti, Vittorio-Taruffo, Michele, Commentario breve al codice di procedura civile, Ed. Cedam, Padova, 2006.

33 Código de processo civil brasileño: “art. 18: -O juiz ou tribunal, de ofício ou a requerimento, condenará o litigante de má-fé a pagarmulta não excedente a um por cento sobre o valor da causa e a indenizar a parte contrária dos

prejuízos que esta sofreu, mais os honorários advocatícios e todas as despesas que efetuou

$\S 1^{\circ}$ - Quando forem dois ou mais os litigantes de má-fé, o juiz condenará cada um na proporção do seu respectivo interesse na causa, ou solidariamente aqueles que se coligaram para lesar a parte contrária.

$\S 2^{\circ}$ - O valor da indenização será desde logo fixado pelo juiz, em quantia não superior a $20 \%$ (vinte por cento) sobre o valor da causa, ou liquidado por arbitramento".

${ }^{34}$ Artículo 280 del Código de Procedimiento Civil. 
prueba y no la rinde o lo hace en forma impertinente, a pagar a su contraria los gastos que las diligencias le ocasionen. Se aprecia que la condena en costas se erige como un ligamen entre las partes del proceso y del modo como se ha explicado, su fundamento se encuentra única y necesariamente en la satisfacción de los intereses pecuniarios de las partes. Una se transforma en acreedora de la otra que por haber sido vencida por resolución denegatoria se convierte en deudora y obligada personalmente al pago de los gastos en que su contendor incurrió por causa del proceso. No debe pensarse que cuando el pago de las costas tiene como antecedente una resolución que obedece a razones éticas se está frente a un deber procesal. (Ver cap. IV.B infra)

\section{DEBERES PROCESALES}

Una primera aproximación a este concepto habla de un termino más amplio que el de obligación y que abarca elementos axiológicos. Una segunda es aquella que, en general, hace sinónimos el concepto de deber al de obligación. Si consideramos estas acepciones en una estructura acotada, cual es la relación jurídica procesal, sólo sirven de orientación. El correcto análisis y descripción de los fenómenos que transitan por el proceso puede hacerse exclusivamente en su interior. Luego, para la acertada clarificación del término se hace necesaria una depuración a través del cotejo con los demás imperativos del proceso ya reseñados.

\section{IV.A. Criterios de diferenciación con el concepto de carga}

Para la comparación entre deberes y cargas procesales recurriré primero a las consecuencias que se producen frente a un caso u otro dentro del proceso. ${ }^{35}$ Los efectos de las cargas ya fueron expuestos y son la preclusión o la mayor probabilidad de pérdida del juicio. El incumplimiento de un deber acarrea una serie de resultados procesales y extraprocesales. ${ }^{36}$ En nuestro ordenamiento positivo la infracción de un deber, por lo general, lleva aparejada una sanción pecuniaria o coactiva. La coacción sólo se encuentra presente en el deber. ${ }^{37}$ Para buscar el fundamento del por qué es necesaria la instauración

${ }^{35}$ Eficaz resulta lo afirmado por Cappelletti que las distingue en orden a que los deberes vienen siempre aparejados de una sanción, impuesta por un ente ajeno al infractor, mientras que la carga no lleva envuelta sanciones. Cappelletti, Mauro, cit. (n. 17), p. 178. Estoy de acuerdo con esta opinión en cuanto a que las cargas, a diferencia de los deberes, no vienen aparejadas de sanciones específicas, pero creo que es más correcto ver la diferencia desde una perspectiva más amplia. Las consecuencias para el infractor en uno u otro caso son claramente distintas. En el caso de la carga procesal el mecanismo consecuencial es la preclusión o la pérdida del litigio. Las consecuencias a la infracción de un deber son todas aquellas que no se traduzcan en el cierre definitivo de espacios procesales o en una mayor probabilidad de sentencia de absolución.

${ }^{36}$ Por ejemplo los artículos 88 y 96 del Codice di procedura civile analizados en esta investigación. Vid. Picó I Junoy, Joan, cit. (n. 16), pp. 265-296.

${ }^{37}$ Cfr. Lent Friedrich, "Obblighi e oneri nel processo civile”, en Rivista di diritto processuale, Cedam, Padova, Volume IX-parte I, anno 1954, p. 50. El término "obliggo" que es el singular, se refiere en italiano 
de una sanción útil es recordar la meditación que elabora Carnelutti:"solamente porque los hombres no tienen en su espíritu más que un átomo de libertad, no logran cumplir su deber si alguien no provee a mandarlos y castigarlos". ${ }^{38}$ Además, la creación de deberes apunta al moralmente correcto desarrollo del proceso que interesa al Estado. ${ }^{39}$ Con esa finalidad no se divisa otro mecanismo de mayor efectividad para el resguardo de aquellos intereses que la imposición de sanciones coactivas o multas. Un autor expone: "el deber procesal representa siempre un imperativo impuesto en el interés del Estado, es decir, en el interés público de la justicia; por ello se puede compeler a su cumplimiento mediante penas pecuniarias o coactivas". ${ }^{40}$ Por otra parte, no se ve inconveniente que en nuestro derecho puedan existir consecuencias extraprocesales a la infracción de deberes. La parte perjudicada por una conducta maliciosa en el proceso puede ejercitar acción de resarcimiento de perjuicios por vía extracontractual conforme a lo previsto en el artículo 2314 del Código Civil. Otra diferencia con la carga, desde la óptica de las secuelas, está en que la sanción, propia del deber, es impuesta por el Estado que es un agente ajeno al infractor. En el caso de la carga su exigibilidad proviene del sujeto, está a su arbitrio cumplir con ella o no. Se impone también como punto de distinción a quien beneficia o interesa la conducta. Los deberes representan imperativos impuestos en beneficio de la comunidad y las cargas en el beneficio de las partes. ${ }^{41}$

Por último, las diferencias se ven desde el punto de vista de los sujetos llamados a cumplir las conductas. Las cargas sólo son ejercidas por las partes. En los deberes estas no son las únicas que asumen su titularidad, la figura del juez juega un papel relevante. ${ }^{42}$ Observa Chiovenda: "el deber fundamental, que forma como el esqueleto de toda relación procesal, es como be visto, el deber del juez, u otro órgano jurisdiccional, de tomar medidas respecto a las peticiones de las partes". ${ }^{43}$ El engarzamiento entre las cargas y el deber del juez se produce así: "el juez tiene que proveer sobre la demanda, y de lo contrario es castigado; la parte tiene que proponer la demanda, y de lo contrario no puede obtener la tutela de su interés en la litis". ${ }^{44} \mathrm{El}$ juez, si bien en el proceso no ejerce cargas, sí deberes. ${ }^{45}$ Además, el juez, independiente de la postura política que se tenga sobre los poderes que a éste le corresponde asumir en

en sentido general al deber jurídico. El texto aparecido en la Rivista es la traducción al italiano del prof. Dr. Marco de Stefano del texto alemán elaborado por Lent, por lo que vale la observación idiomática.

38 Carnelutti, Francesco, Arte del derecho, seis meditaciones sobre el derecho, Ara, Lima, 2006, pp 95-109.

39 Vid. Theodoro Junior, Humberto, "Boa -fé e processo, à litigância de má-fé- Papel do juiz”, en Estudos de Direito Processual Civil, Revista Dos Tribunais, Brasil, 2005, pp. 636-647.

${ }^{40}$ Reimundin, Ricardo, cit. (n.16), p.131; en el mismo sentido, Couture señala que la efectividad en el cumplimiento de los deberes se logra a través de la imposición de sanciones físicas o morales. Couture, Eduardo, cit. (n.13), p. 209.

${ }^{41}$ Cfr. Goldschmidt, James, cit. (n. 5), pp. 91-92.

${ }^{42}$ Cfr. Rosenberg, Leo, cit. (n. 17), p. 11.

43 "Il dovere fondamentale che forma come l'ossatura d'ogno rapporto procesuale, è, come si é visto, il dovere del guidice o altro organo giurisdizionale di provvedere sulle domande delle parti”. Chiovenda, Giuseppe, cit. (n. 25), p. 48.

${ }^{44}$ Carnelutti, Francesco, cit. (n. 15), p. 332.

${ }^{45}$ El fundamento de los deberes del juez se encuentra primordialmente en la Constitución, entre otros, en el principio de inexcusabilidad. 
el proceso, ${ }^{46}$ es innegable que está llamado a ejercer de oficio o a requerimiento de parte una función fiscalizadora del cumplimiento de los deberes. Por otra parte, a diferencia de las cargas, terceros en el proceso igualmente asumen deberes. El sujeto a quien se le solicita la exhibición de un instrumento que está en su poder y se rehúsa sin justa causa a su presentación puede ser apremiado con multas e incluso arrestos; ${ }^{47}$ el testigo que, legalmente citado, comparece a prestar declaración, pero se niega a declarar sin justa causa, puede ser arrestado, ${ }^{48}$ o el perito que puede ser apremiado con multas en caso de que no evacue su informe. ${ }^{49}$

\section{IV.B. Criterios de diferenciación con el concepto de obligación}

No es correcto en el proceso civil asimilar deberes y obligaciones. Desde el punto de vista de los efectos que conllevan los imperativos analizados, todos ellos producen resultados específicos. En el caso de la obligación se genera un vínculo entre las partes para el pago de costas o indemnizaciones, que en último caso dan lugar al cumplimiento compulsivo de la misma, conforme a las reglas generales. En el caso del deber hay un rasgo absolutamente distintivo. En efecto, encontramos deberes que no portan consecuencias específicas, no perdiendo en dicho caso el carácter de tales. En este sentido: "aunque los deberes jurídicos procesales carezcan de punición, lo que no es de normal ocurrencia, no por ello pierden su calidad de tales, aunque es altamente conveniente por el efecto disuasivo que ello conlleva". ${ }^{50}$ Un deber no deja de serlo por no tener aparejada una punición impuesta por el Estado, porque en tal caso puede estimarse como un instrumento sugerente cuyo valor es intrínseco, pues no depende de factores ajenos para su efectividad. En otras palabras, su naturaleza recomendativa interna le está dotando de eficacia, puesto que no es indiferente que la proclamación del deber tenga existencia jurídica o no. Es altamente probable que varios sujetos dirijan su conducta al solo cumplimiento de aquello que el interés social, plasmado en el ordenamiento jurídico, imponga. Ello sin conocer o sin atender al castigo que puede conllevar o no, mismos sujetos que no existiendo ni siquiera la declaración del imperativo no tendrían ni aún el incentivo en el cumplimiento

${ }^{46}$ Esta anotación es porque, como señala Taruffo, los poderes de instrucción del juez en el proceso civil han causado cierta polémica, ya que son considerados por algunos como la asunción de una política antiliberal e incluso totalitaria. Así lo sostiene, por ejemplo, Montero Aroca al referirse a los poderes oficiosos del juez en cuanto a la prueba: "Se trata evidentemente de concepciones ideológicas que priman los poderes del juez en el proceso, en contra de las garantías de las partes y cuya base autoritaria es hoy sobradamente conocida pues respondían al predominio de los poderes del Estado sobre el individuo en la sociedad". Montero Aroca, Juan, La prueba en el proceso civil, Aranzadi, Navarra, 2005, p. 27; también en este sentido: Cipriani, Franco, "Autoritarismo e garantismo nel processo civile", en Rivista di diritto processuale, Cedam, Padova, 1994, pp. 24-61. En contra, Taruffo, Michele, "Poderes probatorios de las partes y del juez en Europa", en revista Ius et Praxis, 2006, vol.12, no.2, pp.95-122; Picó I Junoy, Joan, cit. (n. 16), pp. 29-36.

47 Arts. 349 y 274 del Código de Procedimiento Civil.

${ }^{48}$ Art. 380 del Código de Procedimiento Civil.

49 Art. 420 del Código de Procedimiento Civil.

${ }^{50}$ Peyrano W., Jorge, El proceso civil, principios y fundamento, Astrea, Buenos Aires, 1978, p. 175. 
que su proclamación trae. Sin duda es una eficacia disminuida frente al deber que porta sanciones particulares, pero reitero, no por eso deja de tener valor. ${ }^{51}$ Dentro de los deberes sin consecuencias directas a modo de ejemplo encontramos, en derecho comparado, el deber de veracidad ${ }^{52}$ que impone el Código Procesal Civil alemán (ZPO) en su parágrafo 138 "Deber de declaración sobre los hechos; deber de decir verdad. 1) Las partes deben hacer sus declaraciones sobre cuestiones de hecho en forma completa y adecuada a la verdad". 53 Según algunos autores, refiriéndose al artículo en referencia, las partes tienen el deber de actuar honestamente y no en forma maliciosa y señala que su infracción no produce consecuencias procesales concretas. ${ }^{54}$ En el ordenamiento procesal civil chileno estudiaré que la consagración legislativa implícita, en el actual Código de Procedimiento Civil, del principio de la buena fe procesal, produce esta clase de deberes sin consecuencias directas. (Ver cap. V.B infra)

En cuanto al interés o beneficio procesal que se busca en la instauración del concepto de obligación, al igual que la carga, está en la satisfacción de un beneficio sólo atingente a las partes. En la obligación procesal, al igual que en la relación civil, se crea una relación crédito-débito. El vínculo se genera porque una resolución ordena que el litigante perdedor reembolse los gastos del juicio al ganancioso. El beneficio sólo compete al primero. Los deberes, a diferencia de las obligaciones y las cargas, proveen utilidad al desenvolvimiento transparente del proceso cuyo interés corresponde al Estado. ${ }^{55}$ Por lo anterior, la consecuencia a la infracción de un deber puede producir efectos, pero no ya entre dos personas, como en el caso de la obligación, sino que del infractor para con el Estado a través de la imposición de multas, arrestos o costas. En el Código de Procedimiento Civil, el no cumplimiento del deber de fundar o interponer seriamente una implicancia o recusación trae consigo la imposición de una multa. ${ }^{56}$ Igual sanción se establece al no cumplimiento del deber de alegar en una Corte, cuando un abogado

${ }^{51}$ Vid. Couture, Eduardo, cit. (n. 12) p, 242. Goldschmidt, James, cit. (n. 5), p. 83.

52 Goldschmidt refiriéndose al mismo artículo señala que al haberse instituido un deber sin sanción, este carece de importancia y lo considera como un "cuchillo sin hoja", lo que en todo caso se condice con la visión que sobre el proceso sostuvo este autor -situación jurídica- donde sólo existen cargas procesales. Goldschmidt, James, cit. (n. 5) p. 105.

53 Texto del $\S 138$ de la ZPO vigente al año 2005 y que es el mismo a que se refiere Rosenberg en la fecha de edición del texto en que analiza dicha disposición -1949-, según la traducción realizada por: Pérez Ragone, Alvaro-Ortiz Pradillo, Juan Carlos, Código Procesal Civil alemán, traducción con un estudio introductorio al proceso civil alemán contemporáneo, Konrad Adenauer Stiftung, Montevideo, 2006, p. 195.

${ }^{54}$ En la traducción al español del texto, Rosenberg señala que en todo caso al menos indirectamente, es decir, sin disposición legal que específicamente señale la consecuencia para el caso de infracción, el tribunal debe no estimar las aseveraciones falsas, o estas pueden dar lugar a un engaño procesal constitutivo de delito, o puede incluso intentarse una demanda de indemnización de perjuicios y para el caso del abogado que viola el precepto puede resultarle aplicable una corrección disciplinaria. Rosenberg, Leo, cit. (n. 16), p. 383. Igual observación realiza Lent: Lent Friedrich, "Obblighi e oneri nel processo civile”, en Rivista di diritto processuale, Cedam, Padova, Volume IX-parte I, anno 1954, pp. 150-158.

55 Ibid, cit (n. 9).

56 Art. 122 del Código de Procedimiento Civil. 
se ha anunciado previamente con el relator, ${ }^{57}$ o para el evento de la parte que se rehúsa a cumplir con su deber de declarar bajo juramento acerca de algún hecho relativo a su capacidad para parecer en juicio, o a su personería o al nombre y domicilio de sus representantes. ${ }^{58}$ En este caso además de la multa el desobediente puede ser arrestado hasta dos meses, efecto que también en forma alternativa se establece para aquel que se rehúsa a la exhibición de la cosa que haya de ser objeto de la acción que se trata de entablar. $^{59}$

Es importante hacer una diferenciación. Uno de los efectos previstos para el caso de la infracción de un deber puede ser precisamente la condena en costas. Esto puede parecer un contrasentido si se estableció (Ver cap. III.C supra) que las costas implican una obligación procesal. La paradoja se aclara si observamos la mecánica en que interactúan ambos institutos. El artículo 147 del Código de Procedimiento Civil ordena condenar en costas a todo evento al incidentista contumaz. A esta norma subyace el deber procesal de celeridad. La consecuencia prevista por el legislador para desincentivar la conducta dilatoria frente a la lesión del imperativo implícita, es precisamente la condena en costas. En la práctica el incumplimiento del deber procesal se convierte en la causa de la condena, en virtud de la resolución firme que así lo declare, que a su vez es el origen de la obligación de pago que debe solventar el incidentista, del reembolso de los gastos en que el vencedor incurrió. La objetividad o la falta de consideraciones éticas, rasgo diferenciador con el deber, en el pago de las costas, está en que el fin perseguido por la satisfacción de aquellas, como en todo el sistema de costas, es el reembolso de lo gastado por la contraparte. El deber al mismo tiempo no puede convertirse en una obligación ya que en estricto rigor esta sinonimia temporal no tiene estructura lógica. ${ }^{60}$ En otras palabras, el deber no muta a obligación, que es confundir ambos conceptos, sino, como señalé, la indemnización o el reembolso de lo gastado generan el vínculo obligacional que se impone como una consecuencia a la infracción del deber, en dos momentos y actos procesales distintos.

En cuanto a las personas llamadas a ejecutar las conductas en el caso de la obligación son ejercidas por las partes entre sí, para las cargas los sujetos que componen las partes consideradas individualmente. En lo referente a los deberes valen las mismas consideraciones mencionadas anteriormente en el cotejo con las cargas. Los deberes aparte de los sujetos que integran en forma directa el proceso son asumidos además por terceros y por el juez. Por último, si consideramos el rasgo ético que portan los deberes que se verá en el próximo capítulo, el cotejo de los vectores procesales culmina en el siguiente diagrama:

57 Art. 223 del Código de Procedimiento Civil.

58 Arts. $273 \mathrm{~N}^{\circ} 1$ y 274 del Código de Procedimiento Civil.

59 Arts. $273 \mathrm{~N}^{\circ} 2$ y 276 del Código de Procedimiento Civil.

${ }^{60}$ Es contrario al axioma de la identidad que indica que toda proposición se implica a sí misma. Vid. Losano, Mario (cit. n. 14); Guzmán Brito, Alejandro, Historia de la interpretación de las normas en el derecho romano, Ediciones del instituto de historia del derecho Juan de Solórzano y Pereyra, Santiago, 2000. 


\begin{tabular}{|c|l|l|l|l|l|}
\hline Imperativo & \multicolumn{1}{|c|}{ Efectos } & $\begin{array}{c}\text { Agente } \\
\text { ejecutor }\end{array}$ & \multicolumn{1}{c|}{ Interés } & Titulares & Contenido \\
\hline CARGA & $\begin{array}{l}\text { *Preclusión } \\
\text { *Mayor probabili- } \\
\text { dad de pérdida del } \\
\text { litigio }\end{array}$ & $\begin{array}{l}\text { El mismo } \\
\text { sujeto }\end{array}$ & $\begin{array}{l}\text { Los sujetos que } \\
\text { conforman las } \\
\text { partes conside- } \\
\text { radas en forma } \\
\text { individual }\end{array}$ & Las partes & No axiológico \\
\hline DEBER & $\begin{array}{l}\text { *Intraproceso: } \\
\text {-Multas } \\
\text {-Arrestos } \\
\text {-Costas } \\
\text { *Extraproceso: } \\
\text {-Indemnización }\end{array}$ & El Estado & El Estado & $\begin{array}{l}* \text { Las partes } \\
\text { Terceros }\end{array}$ & Axiológico \\
\hline OBLIGACIÓN & $\begin{array}{l}\text { Creación de un } \\
\text { vínculo para el } \\
\text { cumplimiento del } \\
\text { pago de las costas } \\
\text { e indemnizaciones }\end{array}$ & Las partes & $\begin{array}{l}\text { lananciosa con- } \\
\text { siderada como } \\
\text { acreedora }\end{array}$ & Las partes & No axiológico \\
\hline
\end{tabular}

\section{El PRINCIPIO DE LA BUENA FE COMO FUENTE DE DEBERES PROCESALES}

La concepción que se tenga sobre las fuentes y los principios generales del derecho no es un tema, como tantos otros en materia jurídica, donde haya unanimidad u homogeneidad de posturas. Por ejemplo, el positivismo le asigna escaso valor a estos principios. Otros estudios estiman que la buena fe, al no estar inserta en el orden positivo, no puede constituirse en un principio general del derecho procesal civil. ${ }^{61}$ Si bien esto no es materia de esta prospección, como me referiré a un tópico que comprende dichos conceptos, es menester para el subsiguiente análisis adoptar una postura al respecto. A mi entender, los principios generales constituyen fuente de derecho y cubren un extenso espectro que comprende el suministro de pautas o modelos de conducta, constitutivos de normas jurídicas básicas en aquellos sectores del sistema no colmados por disposiciones legislativas. También son capaces de actuar conjuntamente con las normas legales dotándolas de un determinado sentido. Además cumplen una función orientadora del ente legislativo y finalmente no requieren estar insertos en el plexo normativo para adquirir valor jurídico. ${ }^{62}$

${ }^{61}$ Cfr. Guasp, Jaime-Aragonese, Pedro, Derecho procesal civil, I, Aranzadi, Navarra, 2005, p. 76.

${ }^{62}$ Vid. Alcalde Rodríguez, Enrique, Los principios generales del derecho, su función de garantía en el derecho público y privado chileno, Editorial Universidad Católica de Chile, Santiago, 2003; Borda, Alejandro, La teoría de los actos propios, Abeledo Perrot, Bs. As., 1993, pp. 57-65; López Mesa, Marcelo-Rogel Vide, Carlos, La doctrina de los actos propios, doctrina y jurisprudencia, Reus, Bs. As., 2005. pp. 31-82; Picó I Junoy, Joan, cit. (n. 16), pp. 49 y 50; Prieto Castro y Ferrandiz, Leonardo, Derecho procesal civil, I, Tecnos, Madrid, 1975, p. 40. 
La buena fe es un principio que conforma en gran parte la faz subjetiva del proceso. Por otra parte es un concepto jurídico indeterminado, por lo que sólo pueden efectuarse meras aproximaciones conceptuales sobre la misma. ${ }^{63}$ Su reseña, en este trabajo, obedece a describir el mecanismo de producción de los deberes en el proceso civil y la forma como su influjo axiológico dota al deber de un tinte ético, que es su rasgo más distintivo, comparativamente con los demás imperativos. (Véase cuadro explicativo).

Las obligaciones y cargas no gozan preponderantemente de contenido subjetivo, pues su finalidad está orientada al desenvolvimiento temporal y progresivo de los actos del proceso. Un proceso sin deberes puede igualmente evolucionar en base a cargas y obligaciones aun cuando lo haga de manera poco ética, ya que la existencia de un litigante artero no obsta a la dictación de la sentencia. Insisto en que los deberes jurídicos procesales buscan, más allá del desarrollo del proceso, que este se desenvuelva de una manera éticamente correcta. Se debe tener en cuenta que el deber es una categoría que emana del estadio axiológico del proceso y no el contenido valórico en sí. La aclaración anterior porque puede existir confusión entre dicho contenido y el instrumento por el que se concreta, que es el deber. Se aclara la distinción si se piensa que en virtud del factor ético del proceso se producen en la especie una serie de deberes particulares, como el de mantener una conducta coherente; pero en ningún caso se puede llegar a una solución que señale que existe en el proceso, por ejemplo, un deber de buena fe, ${ }^{64}$ porque sería lo mismo que decir que el género está contenido en la especie.

\section{V.A. Aproximación al contenido del principio de la buena fe procesal}

La buena fe en el proceso no es una temática reciente. Desde antaño ${ }^{65}$ y hasta nuestros días $^{66}$ se observa preocupación sobre el punto. La doctrina nacional se reduce a un par de

${ }^{63}$ Cfr. Picó I Junoy, Joan, cit. (n. 16), p. 69.

${ }^{64} \mathrm{~V} . g r$. "El más típico deber procesal, de nuestra legislación, es el deber de actuar con buena fe en el proceso", Reimundin, Ricardo, cit. (n. 16), p. 131.

${ }^{65}$ Costa, Stefano, $O$ dolo processual em matéria civil e penal (corresponde a la traducción al portugués de la obra "Il dolo processuale in tema civile e penale" de 1930), Paulistanajur, Sao Paulo, 2004; Calogero, Guido, "Probità, lealtà, vericità nel processo civile", en Rivista di diritto processuale civile, Cedam, Padova, volume XVI-parte I, anno 1939, pp. 129-153; Calamandrei, Piero, Studi sul processo civile, Cedam, Padova, 1939, pp. 163-174; Marchetti, Claudio, "Dolo revocatorio e falsa allegazione”, en Rivista di diritto processuale civile, Cedam, Padova, volume XV, anno 1960, pp. 419-445; De Stefano, Giuseppe, "Note sull'abuso del processo", en Rivista di diritto processuale civile, Cedam, Padova, volume XIX-parte I, anno 1964, pp. 582600; Ranieri, Filippo, Rinuncia tacita e Verwirkung, Cedam, Padova, 1971. Destaca la tesis de habilitación profesoral del alemán Walter Zeiss, de 1967, cuya traducción al español se encuentra en: Zeiss, Walter, El dolo procesal, Ejea, Buenos Aires, 1979; En Sudamérica: Fuera del célebre estudio de Couture ya mencionado en este trabajo "El deber de las partes de decir la verdad", De Castro Filho, José Olimpio, Abuso do direito no processo civil, Forense, Rio de Janeiro, 1959.

66 De Mendonca Lima, Alcides, "Abuso do direito de demandar" en Revista de Processo, Revista Dos Tribunais, $\mathrm{N}^{\circ} 19$, junio a septiembre de 1980, pp. 57-66; Rosas Roberto, "Abuso de direito e dano processual” en Revista de Processo, Revista Dos Tribunais, $\mathrm{N}^{\circ} 32$, octubre a diciembre de 1983, pp. 28-48; Taruffo, Michele, "L'abuso del processo: profili comparatistici", en Revista de Processo, Revista Dos Tribunais, N 96 , octubre a diciembre de 1999, pp. 150-169; Pellegrini Grinover, Ada, "Ética, abuso do processo e resistência 
menciones al tema, ${ }^{67}$ pero no existen monografías dedicadas a este importante tópico. La buena fe en materia civil, en nuestro país, se ha estudiado desde un doble punto de vista, aquella llamada "objetiva" establecida en el artículo 1546 que a propósito de los contratos establece el Código sustantivo, y la denominada "subjetiva" establecida en el artículo 702 del mismo Código. No obstante, la ciencia procesal actualmente tiende a la reconducción de una relación jurídica llana a encontrar puntos de encuentro entre los derechos materiales (subjetivos y fundamentales) y el proceso, ${ }^{68}$ no sirve preponderantemente la elaboración de la buena fe al amparo de la ciencia civil, a no ser en aquella parte que se alude a la noción general de un honesto proceder, que en todo caso se encuentra presente en cualquier disciplina jurídica. Lo anterior porque la estructura de los imperativos en el proceso, como se ha establecido en este estudio, tiene medida propia.

Podemos decir que la buena fe alude muy en general a un comportamiento correcto. La dificultad es que el concepto de lo correcto es tan genérico como el de buena fe por lo que definirla así resulta casi una tautología. Cualquier otra definición a priori que se intente, puede caer en la misma cuestión. Sin embargo, no se puede desconocer que cuando se alude a lo correcto, dentro del proceso, al menos en la tradición de cultura $^{69}$ de los operadores jurídicos, existe una significación que dice relación con el comportamiento leal. Atendida la generalidad del término, nociones más precisas, sólo pueden lograrse a través de la creación de patrones por la vía inductiva jurisprudencial o legislativa. Conforme a las explicaciones anteriores, resulta convincente la definición efectuada por el profesor Joan Picó: "Aquella conducta exigible a toda persona, en el marco de un proceso, por ser socialmente admitida como correcta", ${ }^{70}$ porque como él mismo señala: "solo desde esta perspectiva amplia se logra la continua adaptación entre los valores éticos de la sociedad y los valores normativos del ordenamiento, correspondiendo al juez, en cada caso concreto, analizar si la conducta procesal de la parte se adecua a la forma de actuar admitida por la generalidad de los ciudadanos". ${ }^{71}$

às ordens judiciárias: o contempt of court", en Revista de Processo, Revista Dos Tribunais, N 102 , abril a junio de 2001, pp. 219-226; Oteiza, Eduardo, “Abuso de los derechos procesales en América Latina”, en Revista de Processo, Revista Dos Tribunais $\mathrm{N}^{\circ}$ 95, julio a septiembre de 1999, pp. 152-187; De Deus Lima, Patricia Carla, "O Abuso de defesa no processo civil", en Revista de Processo, Revista Dos Tribunais, $\mathrm{N}^{\circ} 122$, abril a junio de 2005, pp. 93-128. Últimamente destaca la tesis del profesor español Joan Picó: Picó I Junoy, Joan, cit. (n. 16).

${ }^{67}$ Romero Seguel, Alejandro, Curso de derecho procesal civil-la acción y la protección de los derechos, cit. (n. 25) pp. 74-77; La jurisprudencia de los tribunales como fuente del derecho, Editorial Jurídica de Chile, 2004, pp. 124-126; "El principio de la buena fe procesal y su desarrollo en la jurisprudencia, a la luz de la doctrina de los actos propios”, en Revista chilena de derecho, vol. 30, No 1, enero-abril de 2003, pp. 168-172.

${ }^{68}$ Marinoni, Luiz Guilherme, Teoría general do processo, I, Revista Dos Tribunais, Sao Paulo, 2006, pp. 396-450.

${ }^{69}$ En el sentido que, a mi entender, Ross asigna a esta idea -la tradición de cultura-, que en general alude a los patrones o elementos culturales presentes en un sujeto inmerso en una cultura deteminada -Ross se refiere al juez- que trascienden al ordenamiento jurídico. Ross, Alf, Sobre el derecho y la justicia, Eudeba, Buenos aires, 1974, pp. 95-104.

${ }^{70}$ Picó I Junoy, Joan, cit. (n. 16), p. 69.

71 Ibíd. 
Más allá de las consideraciones que se pueden tener sobre la buena fe, primariamente no se puede desconocer que el proceso, al ser creación humana, goza a su vez de sus mismas virtudes e imperfecciones, por un lado la aspiración de justicia y por otro el defecto. Esto nos dice que dentro del desarrollo del proceso es inevitable la chicana, y como es repudiada en el escenario humano, de igual forma debe rechazarse en el proceso. ${ }^{72}$ La observancia de ciertos comportamientos de convivencia es una necesidad intuitiva, que dispensa demostración. ${ }^{73}$ Al Estado como organizador de la vida en comunidad le corresponden los mecanismos o reglas para que el proceso se lleve a cabo correctamente, la construcción de los mecanismos de control son los que interesan a la ciencia procesal. Impuesta la creación de una herramienta adecuada para el efectivo resguardo de la buena fe, se originan deberes al interior del proceso. Este imperativo será óptimo en la medida que cristalice en una norma legal que contenga secuelas para el caso de la infracción con un claro efecto disuasivo a los litigantes, ${ }^{74}$ con el plus de que incluso a falta de sanción, ya sea por la omisión o insuficiencia de la disposición legal, al menos el nivel de la proclamación, le dará una eficacia recomendativa. (Ver cap. IV.B supra)

\section{V.B. El reconocimiento implícito en el ordenamiento normativo procesal civil chileno y explícito en la jurisprudencia de la buena fe procesal}

En el aspecto legislativo, en derecho extranjero, el principio ha cristalizado en deberes específicos de probidad y lealtad como en el caso del artículo 88 del Código procesal civil italiano ${ }^{75}$ o el parágrafo 138 de la ZPO ya citado (Ver cap. IV.B supra) También en fórmulas legislativas abiertas que entregan a la jurisprudencia la delimitación de su contenido, como el caso de la ley de enjuiciamiento civil española que en su artículo 247 consagra el respeto a las reglas de la buena fe procesal imponiendo que: "los intervinientes en todo tipo de procesos deberán ajustarse en sus actuaciones a la regla de la buena fe". ${ }^{76}$ En Latinoamérica, el Código procesal civil de Perú establece en su sección IV que: "Las partes, sus representantes, sus abogados y, en general, todos los partícipes en el proceso, adecuan

72 "Por tanto, para permanecer fieles a esta obligación, es necesario persuadirnos cada vez más de que el proceso objeto de nuestros estudios ni es como el legislador lo ha previsto en abstracto, si no como lo hacen vivir, como lo "representan" (en el sentido teatral de la palabra) los hombres, jueces y justiciables, que participan en él en concreto, y que no son muñecos mecánicos construidos en serie, sino hombres vivos, cada uno situado en su mundo individual y social, con sentimiento, intereses, opiniones y costumbres; estas últimas, pueden ser, desafortunadamente, malas costumbres". Calamandrei, Piero, Proceso y democracia, Ed. Ara, Lima, 2006, pp. 174.

${ }^{73}$ Cfr. Theodoro Junior, Humberto, cit. (n. 39), p. 637.

74 "De nada vale que el legislador imponga el deber de decir la verdad si no establece al lado de ese deber, el castigo necesario para quien lo infrinja" Couture, Eduardo, cit. (n.8) p. 242. En este sentido también: Goldschmidt, James, cit. (n. 5), p. 83 .

75 “Art. 88 Dovere di lealta' e di probita' Le parti e i loro difensori hanno il dovere di comportarsi in giudizio con lealta' e probita'. In caso di mancanza dei difensori a tale dovere, il giudice deve riferirne alle autorita' che esercitano il potere disciplinare su di essi". Carpi, Federico-Colesanti, Vittorio -Taruffo, Michele, cit. (n. 32), p. 429.

${ }^{76}$ Montero Aroca, Juan-Calderón Cuadrado, María Pía, Ley de enjuiciamiento civil, Tirant lo blanch, Valencia, 2006. 
su conducta a los deberes de veracidad, probidad, lealtad y buena fe. El Juez tiene el deber de impedir y sancionar cualquier conducta ilícita o dilatoria".

En Chile, aunque no existe una proclamación legislativa expresa sobre la buena fe procesal en el actual ordenamiento procesal civil, este principio goza de pleno reconocimiento. Partimos de la base que el principio general de la buena fe se aplica a todo el sistema jurídico, del que no escapa evidentemente el sistema procesal. Existe evidencia que una de las orientaciones que el legislador tuvo en la codificación está precisamente este principio. En efecto, el mensaje del Código de Procedimiento Civil contiene una serie de pasajes que así lo señalan, al hablar de: "adoptar una serie de medidas encaminadas a hacer ineficaces los expedientes dilatorios a que apela la mala fe para retardar la solución de los pleitos" o cuando expone que: "menester es que se impidan las excusas y evasivas maliciosas" o, en el caso de la imposición de multas para la interposición de incidentes dilatorios: "fijando penas para los litigantes que promovieren y perdieren más de tres incidentes dilatorios, pues hay en tal caso presunción vehemente de mala fe". Estas aspiraciones se plasmaron en normas, siendo las más claras la del artículo 88 que impone multas al litigante que busca la dilación del proceso o que observare mala fe en la interposición de nuevos incidentes; el artículo 147 o los ya citados artículo 122, 223, 273 Nº 1 en relación al artículo 274 y 273 $\mathrm{N}^{\circ} 2$ en concordancia al artículo 276, y artículo 280 del Código de Procedimiento Civil. También encontramos la norma del artículo 531 del Código Orgánico de Tribunales ${ }^{77}$ que exige el resguardo de un deber de decoro en la presentación de escritos. ${ }^{78}$

Si bien no es abundante la jurisprudencia sobre la buena fe exclusivamente procesal, sí se observan casos indiciarios de una evolución en este sentido. Se ha invocado por una parte ${ }^{79}$ como adverso a la buena fe, que su opositor alegue el desconocimiento de la calidad de hija de la beneficiaria de alimentos si en innumerables ocasiones en el proceso la había afirmado. ${ }^{80}$ En otra ocasión, una de las partes en virtud del artículo 55 inciso 2 del Código de Procedimiento Civil, alegó la aplicación de este artículo para pretender el válido emplazamiento de la parte demandada, al rechazarse su pretensión no interpuso recurso alguno en contra de esta resolución denegatoria y procedió a notificar por exhorto la demanda, tal como lo ordenó el juez de la instancia. Al alegar nuevamente en su recurso el artículo 55 inciso 2, el tribunal de apelación estimó que cobra aplicación la doctrina de los actos propios, porque la conducta del apelante que va contra sus comportamientos pretéritos, lo cual no puede aceptarse sin contravenir gravemente al

77 Similar disposición se observa en el artículo 89 del Código procesal civil italiano, en donde Satta ve una subespecie del deber de probidad proveniente del artículo 88 ya citado. Vid. Satta Salvatore-Punzi Carmine, Diritto processuale civile, Cedam, Padova, 2000, p. 118.

${ }^{78} \mathrm{La}$ justificación de la buena fe procesal en el marco supralegal se encuentra en las reglas del debido proceso a la luz del artículo $19 \mathrm{~N}^{\circ} 3$, inciso $5^{\circ}$ del texto constitucional.

79 C.S. 13 de junio de 2007, en www.lexisnexis.cl, número identificador 36590, visitado el 19 de septiembre de 2007.

${ }^{80}$ C.S. 26 de octubre de 2006, en www.lexisnexis.cl, número identificador 35611, visitado el 19 de septiembre de 2007. 
principio de la buena fe ${ }^{81}$ En este mismo sentido se pronunció la Ilustrísima Corte de Apelaciones de Valparaíso al estimar que quien opone excepción de pago fundado en documentos referidos a una obligación distinta a la que motiva la deuda que subyace al juicio lo hace con infracción a la buena fe procesal. ${ }^{82}$ La Corte de Apelaciones de Concepción ha declarado que el actor que pretende reactivar el proceso después de una prolongada inactividad, a través de una solicitud de nulidad procesal, actúa en contra de la buena fe procesal. ${ }^{83}$ Un fallo de la Corte de Apelaciones de Santiago ha sido vehemente en su reconocimiento al decir que: "en nuestro ordenamiento procesal, tiene aplicación el principio de probidad o de buena fe, que exige a los contendientes una actuación leal en el uso de pretensiones, defensas o recursos, sancionándose cualquier exceso en el uso de expedientes dilatorios o pretensiones infundadas". 84

El problema es, que al no estar consagrada expresamente la buena fe procesal, los tribunales y los operadores jurídicos no gozan del grado de certeza y difusión que su consagración legislativa expresa conlleva y tampoco se evita la duda o discusión sobre su vigencia. Más relevante resulta el hecho que al no establecerse una sanción de carácter general que cubra todas las hipótesis en que se infrinjan los deberes que emanan de este principio, aparte de no existir un real desincentivo de la conducta maliciosa en el proceso, la buena fe, conforme a su estado legislativo actual, genera sólo deberes (véase apartado IV.B), sin sanción concreta y por ende, con una eficacia disminuida. Existe la necesidad de una reforma legislativa que no deje lugar a dudas en la aplicación de este principio y que contenga los mecanismos para hacerla efectiva. Que también permita, en virtud de una cláusula abierta, por la vía jurisprudencial y doctrinal, delimitar claramente los deberes específicos que se le imponen a las partes en virtud de esta directriz. Estos cuestionamientos son recogidos por el anteproyecto del Código Procesal Civil. ${ }^{85}$

${ }^{81}$ C.S. 19 de abril de 2005, en www.lexisnexis.cl, número identificador 32041, visitado el 19 de septiembre de 2007.

82 C. A. de Valparaíso, 28 de octubre de 2004, en www.lexisnexis.cl, número identificador 31674, visitado el 19 de septiembre de 2007.

${ }^{83}$ C. A. de Concepción, 3 de julio de 2000, en www.lexisnexis.cl, número identificador 22144, visitado el 19 de septiembre de 2007.

${ }^{84}$ C. A. de Santiago, 9 de noviembre de 1992, en www.lexisnexis.cl, número identificador 20074 , visitado el 19 de septiembre de 2007.

${ }^{85}$ Artículo $8^{\circ}$ del anteproyecto: "Buena fe procesal. Las partes, los terceros y, en general, todos quienes deben acudir ante los tribunales deben ajustar su conducta a la dignidad de la justicia, al respeto de los derechos fundamentales de la persona humana y a la lealtad y buena fe procesal.

El tribunal, de oficio o a petición de partes, podrá adoptar durante el desarrollo del proceso todas las medidas que estime pertinentes para impedir o sancionar toda conducta u omisión que importe un fraude procesal, colusión o cualquiera otra conducta ilícita o dilatoria.

Si los tribunales estimaren que alguna de las partes o tercero han actuado conculcando las reglas de la buena fe procesal, podrá imponerle, de forma motivada, y respetando el principio de proporcionalidad, una multa entre 10 y 100 UTM. En ningún caso la multa podrá superar la tercera parte de la cuantía del litigio. En caso de reincidencia, se podrá aplicar el doble de la multa.

Para determinar la cuantía de la multa el tribunal deberá tener en cuenta las circunstancias de hecho que se trate, así como los perjuicios que al procedimiento o a las otras partes se hubieren podido causar". Cit. (n. 41). 


\section{El DEBER DE COHERENCIA}

El examen de cada uno de los deberes jurídicos que emana del principio de la buena fe procesal implicaría efectuar un trabajo que excede con creces los objetivos planteados en la introducción. Es por ello que intentaré enunciar el deber que con mayor claridad aparece en la jurisprudencia nacional, sin perjuicio que por vía legislativa se divisa fluidamente el deber de celeridad cubierto en buena medida por el artículo 88 del Código procedimental.

La doctrina civil ${ }^{86}$ ha elaborado un instituto denominado "la doctrina o teoría de los actos propios". En ella se encuentra presente el brocardo venire contra factum proprium non valet. Se han propuesto conceptos: "constituye una regla de derecho derivada del principio general de la buena fe, que sanciona como inadmisible toda pretensión lícita pero objetivamente contradictoria con respecto al propio comportamiento anterior efectuado por el mismo sujeto". 87 Se citan como requisitos de procedencia: Una situación jurídica preexistente; una conducta del sujeto, jurídicamente relevante y plenamente eficaz, que suscite en la otra parte una expectativa seria de comportamiento futuro y una pretensión contradictoria con esa conducta, atribuible al mismo sujeto. Verificados estos requisitos el efecto que producirá es que la conducta contradictoria con un acto anterior se reputará irrelevante y se estará, en consecuencia, a la primera manifestación.

En el ámbito del proceso ya en el siglo pasado, en la década del 60, en la monografía de Walter Zeiss sobre el dolo procesal, se observa una elaboración de esta doctrina circunscrita exclusivamente al proceso. ${ }^{88}$ En nuestro país el profesor Romero Seguel ha hecho algunas referencias, ${ }^{89}$ y ha enunciado una cercanía de la doctrina al proceso, pero aún no se ha efectuado un estudio que intente una sistematización dogmática de dicho instituto aplicado al ordenamiento procesal civil. La jurisprudencia ha avanzado un poco más rápido que la doctrina y ha reconocido la tesis en varias oportunidades.

\footnotetext{
${ }^{86}$ Sobre esta doctrina en el ámbito civil nacional se encuentran los siguientes trabajos: López Santa María, Jorge, "Los intereses devengados por indemnización contractual de perjuicios. Doctrina de los actos propios o estoppel", en Revista de Derecho y Jurisprudencia, t. LXXXII, N 2, parte $1^{\text {a }}$, Santiago de Chile, mayo-agosto de 1985, pp. 33 y ss; Ekdhal Escobar, María Fernanda, La doctrina de los actos propios, Editorial Jurídica, Santiago, 1989; Fueyo Lanieri, Fernando, Instituciones de derecho civil moderno, Editorial Jurídica, Santiago, 1990. En derecho comparado, también en el ámbito civil, se encuentran monografías referidas exclusivamente a este tópico, entre otras: Puig Brutau, José, Estudios de Derecho Comparado. La doctrina de los actos propios, Ariel, Barcelona, 1951; Díez Picazo-Ponce de León, Luis, La doctrina de los propios actos, Ed. Bosch, Barcelona, 1963; López Mesa, Marcelo-Rogel Vide, Carlos, la doctrina de los actos propios, doctrina y jurisprudencia, Ed. Reus, Buenos. Aires, 2005; Borda, Alejandro, La teoría de los actos propios, Ed. Abeledo Perrot, Buenos Aires, 1993.

${ }^{87}$ Borda, Alejandro, La teoría de los actos propios, Ed. Abeledo Perrot, Buenos Aires, 1993, p. 56.

${ }^{88}$ Vid. Zeiss, Walter, El dolo procesal, Ejea, cit. (n. 65), pp. 98-121.

${ }^{89}$ A propósito de los límites al derecho de acción: Romero Seguel, Alejandro, cit. (n. 25), pp. 74 y 75; del mismo autor respecto al análisis de una jurisprudencia de la Corte Suprema: La jurisprudencia de los tribunales como fuente del derecho, cit. (n. 81), pp. 124-126; "El principio de la buena fe procesal y su desarrollo en la jurisprudencia, a la luz de la doctrina de los actos propios”, en Revista chilena de derecho, Vol. 30, N ${ }^{\circ} 1$, enero-abril de 2003, pp. 168-172.
} 
Valgan los pronunciamientos de los tribunales analizados en el capítulo anterior, pues en todos ellos se hace alusión a la doctrina de los propios actos en relación a problemas netamente procesales. Existen, además, casos aún más claros como la sentencia de la Corte de Apelaciones de Santiago, que estableció que: "Si bien artículo 17 inciso $2^{\circ}$ del Código de Procedimiento Civil permite que puedan proponerse en una misma demanda 2 ó más acciones incompatibles para que sean resueltas una como subsidiaria de la otra, tal posibilidad no puede llevar al extremo de postular coetáneamente pretensiones que se sustentan en hipótesis tan irreconciliables como lo son la que, por una parte se basa en la existencia de un contrato de arrendamiento y por la otra, en la ausencia de todo vínculo contractual". Esta sentencia en uno de sus considerandos hace expresa mención que el demandante al obrar así pugna con la doctrina de los actos propios. ${ }^{90}$ Además se destaca un fallo de la Corte Suprema que rechaza el recurso de casación sobre una sentencia confirmada por la Ilustrísima Corte de Apelaciones de Valparaíso que en un caso sobre divorcio, para enervar la acción, la demandada interpuso excepción de no pago de alimentos, al tenor del artículo 55 inciso $3^{\circ}$ de la ley $\mathrm{N}^{\circ}$ 19.947. En ese expediente el tribunal consignando expresamente que la controversia concierne a esta teoría en materia procesal, estima que va contra sus propios actos la alimentaria que después de 30 años de inactividad procesal y frente a su silencio, viene a señalar que los alimentos que le asisten no se habían pagado, si ésta nunca accionó en contra del actor. Resulta interesante en esta sentencia que incluso hace aplicable la doctrina a una situación silenciosa u omisiva previa del demandante. ${ }^{91} \mathrm{La}$ jurisprudencia citada hace aplicación de la teoría en virtud del principio general de la buena fe que viene a llenar el vacío legal actual, porque precisamente el ordenamiento procesal civil no soluciona estos puntos.

Teniendo presente todo lo que se ha dicho a lo largo de este estudio sobre las fronteras del proceso, no parece para la ciencia procesal prima facie, que pueda efectuarse al interior del proceso un trasplante puro y simple de las condiciones elaboradas por juristas civiles para la doctrina de los actos propios. Distinto es analizar una conducta contradictoria en la relación sustantiva que en la relación procesal, puesto que cada una tiene parámetros propios. No es el objeto de este artículo ahondar sobre el punto, pero quiero dejar de manifiesto la necesidad de construir una tesis que reúna requisitos exclusivamente procesales. La inquietud surge, además de lo recién expuesto, porque el proceso concebido como sistema externo, es una exposición ordenada de una disciplina jurídica que consta de axiomas y de teoremas y cuyos requisitos son la coherencia, la

${ }^{90}$ C. A. de Santiago de 19 de junio de 1993, en www.lexisnexis.cl, número identificador: 20196, visitado el 15 de agosto de 2006.

${ }^{91}$ En lo pertinente señala: "Situación similar es la que se produce exclusivamente con la demandada quien nunca solicitó para sí una pensión al demandante por lo que, luego de 30 años, resulta sorprendente que pretenda hacer valer su derecho para enervar la pretensión del actor. Aquello es contrario a la regla del venire contra factum proprium non valet. Como se aprecia nos referimos aquí a la doctrina de los actos propios en el ámbito netamente procesal". Sentencia de la C. S. dictada en autos rol N 3671-06, sobre sentencia de primera instancia de fecha 27 de octubre de 2006, en causa rit 1380- 05, caratulados "Olguín con Vega". 
completitud y la independencia de axiomas y su necesidad. ${ }^{92}$ En el caso del derecho procesal los axiomas pueden ser cualquiera de sus fuentes, que conforman los puntos de partida del discurso, y sus teoremas serán los postulados o predicados que sobre ellos se hagan. Los conectores de la construcción teórica son los tres universales enunciados de la lógica y sobre los que se ha formado esta disciplina en su función sistemática: La no contradicción, la identidad y el tercio excluido. ${ }^{93}$ Estatuido lo anterior el deber de coherencia se asienta sobre el postulado de la no contradicción, porque la ciencia procesal como un sistema que busca una armonía no puede tener contrasentidos y en consecuencia debe proscribir cualquier intento de inconexión. No obstante, la mecanicidad que esto implica por sí sola no sirve; la conducta del individuo no puede atender a un factor puramente objetivo cual es incurrir en contradicción, si no se toma en cuenta su finalidad, en cuya faz subjetiva entra la valoración de su buena o mala fe y en consecuencia del principio.

\section{CONSIDERACIONES FINALES}

Cualquier observador diría, como expuse en la introducción, que la relación procesal se compone de los mismos elementos que la relación sustantiva. Lo anterior es efectivo, porque el proceso, como sistema, se desarrolla en base a una serie de conductas ciertas y verificables clasificadas en las categorías conductuales estudiadas. También, de manera más sutil, en una simetría en el juego de dichos factores. En este orden de ideas, la relación procesal, que es por cierto también una relación entre personas, no sólo se sostiene sobre el desenvolvimiento mecánico de aquellos elementos considerados objetivamente. En toda relación existe un aspecto subjetivo a considerar que es aquel que de cierta manera guía un correcto y moralmente necesario desenvolvimiento en ellas. El proceso, por tanto, también está cubierto por este nivel subjetivo, porque también requiere de una directriz ética que le sirva de guía en la consecución de los actos que la conforman. La faz axiológica del proceso, distinta al ingrediente axiológico de todas las normas jurídicas, se concreta a través de los deberes procesales que nacen de las consideraciones éticas que el legislador prevé cuando dicta preceptos que contienen el imperativo, o, a falta o insuficiencia de ley, cobra aplicación la creación jurisprudencial que en ese caso se constituye en su origen. Los deberes procesales no actúan aisladamente. Su progreso cobra fuerza inicial a través del ejercicio de un derecho subjetivo procesal, sustentándose diferenciadamente y en yuxtaposición con las cargas y las obligaciones. La interconexión de todos los factores propende a la armonía que cualquier sistema debe contener.

Este marco teórico que habla de un estadio ético en el proceso se verifica en distintas legislaciones a través de la consagración expresa de la buena fe. El principio actualmente existe en nuestra legislación pero a nivel de enunciado tácito, más adecuada resulta,

\footnotetext{
92 Ibid (cit. n. 14).

${ }^{93}$ Ibid (cit. n. 60).
} 
como se vio, su concreción legislativa. En este sentido, su inserción en el articulado del anteproyecto indica un futuro auspicioso del proceso civil chileno. Un simple análisis prospectivo revela que, entre otras ventajas, algunas que se han analizado en este estudio, la buena fe permitirá otorgar al proceso una mayor transparencia. Además, su inclusión a modo la cláusula general permite proveer de mayor libertad a los tribunales para que vayan creando deberes particulares o efectivizando los deberes ya creados que no cuentan todavía con una consecuencia directa positivamente establecida para el caso de su infracción, como el de coherencia descrito en este estudio.

\section{BIBLIOGRAFÍA}

Alvaro de Oliveira, Carlos Alberto, "Poderes del juez y visión cooperativa del proceso", en Revista peruana de derecho procesal, VII, Palestra, Lima, 2005, pp. 17-42.

Alcalá-Zamora y Castillo, Niceto, "Ensayos de derecho procesal”, en Revista de jurisprudencia argentina, Buenos Aires, 1944.

Alsina, Hugo, Tratado teórico práctico de derecho procesal civil y comercial, I, Ediar, Buenos Aires, 1956.

Allorio, Enrico, El ordenamiento jurídico en el prisma de la declaración judicial, Ejea, s. d., pp. 111-115.

Baptista Da Silva, Ovidio A., Jurisdicción y ejecución en la tradición romano-canónica, Palestra, Lima, 2005.

Borda, Alejandro, La teoría de los actos propios, Abeledo Perrot, Buenos Aires, 1993.

Calogero, Guido, "Probità, lealtà, vericità nel processo civile", en Rivista di diritto processuale civile, Cedam, Padova, volume XVI-parte I, anno 1939, pp. 129-153.

Calamandrei, Piero, Los estudios de derecho procesal en Italia, Ara, Lima, 2006.

- Proceso y democracia, Ed. Ara, Lima, 2006.

- Studi sul processo civile, Vol. 4, Cedam, Padova, 1939.

Cappelletti, Mauro, El proceso civil en el derecho comparado, Ara, Lima, 2006.

- Las sentencias y las normas extranjeras en el proceso civil, Ara, Lima, 2006.

Carnelutti, Francesco, Sistema de derecho procesal civil,I, Ed. Uthea, Buenos Aires, 1944

- Sistema de derecho procesal civil, II, Uthea, Buenos Aires, 1944.

- Sistema de derecho procesal civil,III, Uthea, Buenos Aires, 1944.

- Sistema de derecho procesal civil,IV, Uthea, Buenos Aires, 1944.

- Instituciones del proceso civil. I, Ejea, Buenos Aires, 1959.

- Arte del derecho, seis meditaciones sobre el derecho, Ara, Lima, 2006.

- "Arte del diritto", en Rivista de diritto processuale civile, Cedam, Padova, Volume XI - parte I, anno 1934-XII, pp. 2-25.

Carpi, Federico-Colesanti, Vittorio-Taruffo, Michele, Commentario breve al codice di procedura civile, Cedam, Padova, 2006.

Chiovenda, Giuseppe, Istituzioni di diritto processuale civile, I, Dott. Eugenio Jovene, Napoli, 1960.

- La acción en el sistema de los derechos, Edeval, Valparaíso, 1992.

Cipriani, Franco, "Autoritarismo e garantismo nel processo civile", en Rivista di diritto processuale, Cedam, Padova, 1994, pp. 24-61.

Comoglio, Luigi Paolo-Ferri, Corrado-Taruffo, Michele, Lezioni sul processo civile, Vol. 1, Il mulino, Bologna, 1995, p. 708. 
Costa, Stefano, O dolo processual em matéria civil e penal, Paulistanajur, Sao Paulo, 2004.

Couture, Eduardo, Introducción al estudio del proceso civil, Arayú, Buenos Aires, 1953.

- Fundamentos del derecho procesal civil, Depalma, Buenos Aires, 1958.

- Estudios de derecho procesal civil, III, Ediar, Buenos Aires, 1948.

De Mendonca Lima, Alcides, "Abuso do direito de demandar" en Revista de Processo, Revista Dos Tribunais, $\mathrm{N}^{\circ} 19$, junio a septiembre de 1980, pp. 57-66.

Díez-Picazo Ponce de León, Luis, La doctrina de los propios actos, Bosch, Barcelona, 1963.

De Stefano, Giuseppe, "Note sull'abuso del processo", en Rivista di diritto processuale civile, Cedam, Padova, volume XIX-parte I, anno 1964, pp. 582-600.

De Castro Filho, José Olimpio, Abuso do direito no processo civil, Forense, Rio de Janeiro, 1959.

De Deus Lima, Patricia Carla, "O Abuso de defesa no processo civil”, en Revista de Processo, Revista Dos Tribunais, $\mathrm{N}^{\circ} 122$, abril a junio de 2005, pp. 93-128.

D’Ors, Alvaro, Una introducción al estudio del derecho, Ediciones. Universitarias de Valparaíso, Valparaíso, 2003.

Dottri Doria, Rogeira, “A litigancia de má-fé e a aplicacao de multas", en Estudos de Direito Processual Civil, Ed. Revista Dos Tribunais, Brasil, 2005, pp. 649-655.

Fueyo Laneri, Fernando, Instituciones de derecho civil moderno, Editorial Jurídica, Santiago, 1990.

Goldschmidt, James, Principios generales del proceso, I: Teoría general del proceso, Ejea, Buenos Aires, 1961.

Goyard Fabre, Simone, "Los derechos del hombre: orígenes y prospectiva, problemas actuales de los derechos fundamentales", en Revista del instituto de derechos humanos Bartolomé de Las Casas, Madrid, 1994.

Guasp, Jaime-Aragonese, Pedro, Derecho procesal civil, I, Aranzadi, Navarra, 2005.

- Derecho procesal civil, II, Ed. Aranzadi, Navarra, 2005.

GuZMÁn BRITO, Alejandro, Historia de la interpretación de las normas en el derecho romano, Ediciones del Insituto de Historia del Derecho Juan de Solórzano y Pereyra, Santiago, 2000.

Giannozzi, Giancarlo, La contumacia nel processo civile, Giuffrè, Milano, 1963.

LENT Friedrich, "Obblighi e oneri nel processo civile", en Rivista di diritto processuale, Cedam, Padova, Volume IX-parte I, anno 1954, pp. 150-158.

López Mesa, Marcelo, La doctrina de los actos propios en la jurisprudencia, Depalma, Buenos Aires, 1997.

López Mesa, Marcelo-Rogel Vide, Carlos, La doctrina de los actos propios, doctrina y jurisprudencia, Reus, Buenos Aires, 2005.

López Santa María, Jorge, "Los intereses devengados por indemnización contractual de perjuicios. Doctrina de los actos propios o estoppel", en Revista de Derecho y Jurisprudencia, t. LXXXII, N² ${ }^{\circ}$, parte $1^{a}$, Santiago de Chile, mayo-agosto de 1985 , p. 33 y ss.

Losano, Mario G., Sistema e struttura nel diritto, I: Dalle origine alla scuola storica, Giuffrè, Milano, 2002

MarchetTi, Claudio, "Dolo revocatorio e falsa allegazione", en Rivista di diritto processuale civile, Cedam, Padova, volume XV, anno 1960, pp. 419-445.

Marinoni, Luiz Guilherme, Curso de Processo Civil, Teoria general do processo, Vol. 1, Revista dos Tribunais, Sao Paulo, 2006, pp. 511.

- Curso de Processo Civil, Processo de Conbecimento, Vol. 2, Revista dos Tribunais, Sao Paulo, 2006, pp. 511.

Masciotra, Mario, La conducta procesal de las partes, Ad-hoc, Buenos Aires, 2005.

Maurino, Alberto Luis, Abuso del derecho en el proceso, La ley, Buenos. Aires, 2001. 
Monroy Gálvez, Juan, Introdución al proceso civil, Temis, Bogotá, 1996.

Montero Aroca, Juan - Calderón Cuadrado, María Pía, Ley de enjuiciamiento civil, Tirant Lo Blanch, Valencia, 2006.

Montero Aroca, Juan, La prueba en el proceso civil, Aranzadi, Navarra, 2005.

Morello, Augusto Mario, Estudios de derecho procesal, Abeledo Perrot, 1998.

OтteízA, Eduardo, "Abuso de los derechos procesales en América Latina”, en Revista de Processo, Revista Dos Tribunais, No 95, julio a septiembre de 1999, pp. 152-187.

Pellegrini Grinover, Ada, "Ética, abuso do processo e resistência às ordens judiciárias: o contempt of court", en Revista de Processo, Revista Dos Tribunais, N 102 , abril a junio de 2001, pp. 219-226.

PÉrez Ragone, Álvaro J., "En torno al procedimiento monitorio desde el derecho procesal comparado europeo: caracterización, elementos esenciales y accidentales”, en Revista de Derecho, Universidad Austral de Chile, vol. XIX, julio 2006, pp. 205-235.

Pérez Ragone, Álvaro J.-Ortiz Pradillo, Juan Carlos, Código Procesal Civil alemán, traducción con un estudio introductorio al proceso civil alemán contemporáneo, Konrad Adenauer Stiftung, Montevideo, 2006.

Peyrano W., Jorge, El proceso civil, principios y fundamentos, Astrea, Buenos Aires, 1978.

Picó I Junoy, Joan, El principio de la buena fe procesal, Bosch, Barcelona, 2003.

Prieto Castro y Ferrandiz, Leonardo, Derecho procesal civil, I, Tecnos, Madrid, 1975.

Ranieri, Filippo, Rinuncia tacita e Verwirkung, Cedam, Padova, 1971.

Redenti, Enrico, Diritto proccesuale civile, I, Giuffrè, Milano, 1957.

Reimundin, Ricardo, Derecho procesal civil, I, Viracocha, Buenos Aires, 1956.

- Derecho procesal civil, II, Viracocha, Buenos Aires, 1956.

Rosas, Roberto, "Abuso de direito e dano processual" en Revista de Processo, Revista Dos Tribunais, $\mathrm{N}^{\circ} 32$, octubre a diciembre de 1983, pp. 28-48.

Romero Seguel, Alejandro, Curso de derecho procesal civil - la acción y la protección de los derechos, I, Editorial Jurídica de Chile, 2006.

- La jurisprudencia de los tribunales como fuente del derecho, Editorial Jurídica de Chile, 2004.

- Acumulación inicial de acciones, artículos 17 y 18 del Código de Procedimiento Civil, Ed. Jurídica Conosur, Santiago, 2000.

- $\quad$ "El principio de la buena fe procesal y su desarrollo en la jurisprudencia, a la luz de la doctrina de los actos propios", en Revista chilena de derecho, vol. 30, N 1, enero-abril de 2003 , pp. 168-172.

Rosenberg, Leo, Tratado de derecho procesal civil, I, Ejea, Buenos Aires, 1955.

Ross, Alf, Sobre el derecho y la justicia, Eudeba, Buenos Aires, 1974.

SATtA, Salvatore, Diritto processuale civile, Cedam, Padova, 1957.

Satta, Salvatore-Punzi, Carmine, Diritto Processuale Civile, Cedam, Padova, 2000.

SEnTís Melendo, Santiago, Teoría y práctica del proceso: ensayos de derecho procesal, I, Ed. Ejea, Buenos Aires, 1959.

- Teoría y práctica del proceso: ensayos de derecho procesal, II, Ejea, Buenos Aires, 1959.

SpInOZA, Baruch, Tratado teológico político, Alianza, Madrid, 1986.

TARuffo, Michele, "Poderes probatorios de las partes y del juez en Europa", en revista Ius et Praxis, 2006, vol.12, no. 2, pp. 95-122.

- "L'abuso del processo: profili comparatistici", en Revista de Processo, Revista Dos Tribunais, No 96, octubre a diciembre de 1999, pp. 150-169.

Tavolari Oliveros, Raúl, Estudios de derecho procesal, Edeval, Valparaíso, 1990.

Theodoro Junior, Humberto, "Boa -fé e processo, à litigância de má-fé- Papel do juiz”, en Estudos de Direito Processual Civil, Revista Dos Tribunais, Brasil, 2005, pp. 636-647. 
Von BüLow, Oskar, Excepciones y presupuestos procesales, Ejea, Buenos Aires, 1964.

VILley, Michel, Estudios en torno a la noción de derecho subjetivo, Ediciones Universitarias de Valparaíso, Valparaíso, 1976.

WACH, Adolf, Conferencias sobre la ordenanza procesal civil, Ara, Lima, 2006.

Zeiss, Walter, El dolo procesal, Ejea, Buenos Aires, 1979. 